\title{
Desenvolvimento e construção de leito de jorro para recobrimento de partículas de ureia
}

\section{Development and construction of a spouted bed to covering urea particles}

Arthur de Souza Oliveira; Fernanda Siena Ferrato; Fernando Lucas Tibola; Guilherme de Freitas; Isabela Fernandes Rodrigues; Nicoli Rodrigues de Oliveira; Silas Tavares Silva; Thaise Fernanda Braga; Kássia Graciele dos Santos; Davi Leonardo de Souza*

\author{
Universidade Federal do Triângulo Mineiro, Departamento de Engenharia Química \\ *e-mail: davi.souza@uftm.edu.br
}

\begin{abstract}
RESUMO: Os fertilizantes nitrogenados, como a ureia, têm sido bastante utilizados como fonte de micro e macronutrientes para as plantas. Porém, o nitrogênio presente no fertilizante acelera sua volatilização, sendo necessário aplicar técnicas como o recobrimento, para retardar este processo. Dessa forma, o objetivo deste trabalho foi o desenvolvimento e construção de um leito de jorro para o recobrimento de ureia. O sistema era composto por um soprador; um manômetro tubo em U para medição da queda de pressão do leito, um anemômetro de fio quente para aferição da vazão de ar, um leito de jorro cônico-cilíndrico e um bico borrifador para aspersão da solução recobridora. Esta solução possui composição (em massa): 0,5\% de gelatina, $0,5 \%$ de amido, $3 \%$ de glicerina, $9 \%$ de talco e $87 \%$ de água. Inicialmente, caracterizou-se as partículas de ureia, quanto ao tamanho, forma e densidade. Em seguida, foi levantado o comportamento fluidodinâmico do leito, obtendo-se a curva característica que relaciona a queda de pressão em função da vazão de ar, para uma massa inicial de sólidos de $600 \mathrm{~g}$ de ureia. A condição de jorro mínimo obtida apresentou vazão de $0,0038 \mathrm{~m}^{3} / \mathrm{s}$ e queda de pressão de $176,5 \mathrm{~Pa}$. Foi realizado o experimento de recobrimento do fertilizante em uma vazão de ar $20 \%$ superior ao mínimo jorro. $O$ leito de jorro se mostrou eficiente no recobrimento do fertilizante estudado. Porém, para o melhor funcionamento do processo, observou-se a necessidade de acrescentar um sistema de aquecimento do ar, para melhorar a evaporação da água da solução recobridora, evitando que fiquem grudadas no leito.
\end{abstract}

Palavras-chave: Fertilizantes; Leito de jorro; Nitrogenados; Recobrimento; Projeto experimental.

ABSTRACT: The nitrogen fertilizers, such as urea, have been widely used as micro and macro nutrients source. However, the nitrogen present in the fertilizer is quickly lost to environment, because of its volatilization, so it is necessary to apply some techniques, such as coating, to minimize this process. Thus, the aim of this work was the development and construction of a spouted bed to covering fertilizer particles. The system was compound by a blower, an U-tube manometer for measuring the pressure drop, a hot wire anemometer to evaluate the air flow, a conical-cylindrical spouted bed and a spray nozzle for sprinkling of the recovery solution. The solution has the composition (in mass): $0.5 \%$ of gelatin, $0.5 \%$ of starch, $3 \%$ of glycerin, $9 \%$ of talcum and $87 \%$ of water. Initially, the urea particles were characterized by size, shape and density. Then, the fluid dynamic behavior of the bed was obtained, obtaining the characteristic curve that relates the pressure drop as a function of the air flow, for an initial mass of $600 \mathrm{~g}$ urea solids. The minimum spout obtained showed a flow rate of $0.0038 \mathrm{~m}^{3} / \mathrm{s}$ and a pressure drop of $176.5 \mathrm{~Pa}$. It was carried out the experiment of coating the fertilizer with an air flow $20 \%$ higher than the minimum spout. The spout bed was efficient in coating the studied fertilizer. However, for the better functioning of the process, it was observed the need to add an air heating system, to improve the water evaporation at the recovery solution.

Keywords: Fertilizer; Spouted Bed; Nitrogen; Covering; Experimental project. 
INTRODUÇÃO

Devido a fatores climáticos, os solos tropicais geralmente são bastante ácidos. Além disso, observa-se um aumento da população mundial, que resulta na necessidade do aumento da produção de alimentos e energia. Dessa forma, há a necessidade de fornecer nutrientes aos solos, resultando em uma maior demanda por fertilizantes. Dentre os macronutrientes, tem-se o nitrogênio, que além de ser constituinte de aminoácidos e proteínas, participa ativamente de todas as etapas do ciclo vegetal (DA MOTA, 2013).

A ureia é um dos principais fertilizantes nitrogenados, pois possui elevada concentração de $\mathrm{N}$ (de 44 a 46\%), bem como um menor custo de transporte e aplicação por unidade de nutriente (PROCHNOW, 2007). No Brasil, a ureia utilizada é oriunda predominantemente de importações (74\%), representando aproximadamente $51 \%$ do fertilizante utilizado no país, em 2010 (STAFANATO, 2013).

Todavia, ela é bastante propensa a perdas de nitrogênio por volatilização, podendo chegar a até $80 \%$ do total aplicado (DA MOTA, 2013). As perdas por volatilização ocorrem porque esse fertilizante pode ser rapidamente hidrolisado, em um tempo de dois a três dias, pela ação da enzima urease, que é produzida por microrganismos do solo e por restos de vegetais e animais (STAFANATO, 2013).

Assim, existe o incentivo para o desenvolvimento de processos de recobrimento que propiciem a liberação gradual dos fertilizantes no solo, reduzindo perdas e aumentando sua disponibilidade para os vegetais. Uma possibilidade é o controle da liberação por filmes poliméricos, permitindo que os nutrientes sejam liberados a uma taxa controlada pela porosidade e permeabilidade do filme (DONILDA, 2000).

O leito de jorro é um equipamento que promove a interação sólido-fluido e é constituído por uma parte cilíndrica, e uma parte cônica com diâmetro reduzido, pela qual se injeta a fase fluida. Quando um fluido é alimentado na base de um leito contendo partículas, ele percorre sua zona central, promovendo o arraste das partículas até o topo, com formação de um movimento de jorro (SANTOS et al., 2009). Este equipamento foi desenvolvido, inicialmente, para a secagem de produtos granulares, mas também tem sido utilizado no recobrimento de partículas.

A técnica de recobrimento em leito de jorro baseia-se na injeção de ar aquecido na base do leito, com consequente formação do jorro, seguida pela atomização de uma determinada solução que recobrirá as partículas, na região de fonte. Em virtude da presença de ar sob elevada temperatura, a solução recobridora é depositada e seca sobre as partículas, levando à formação de uma camada delgada. Logo, a espessura deste filme aumenta a cada vez que as partículas passam pela zona de aspersão (DONILDA, 2000).

Dessa forma, os objetivos deste trabalho podem ser divididos em dois pontos. $\mathrm{O}$ primeiro seria a construção de um leito de jorro para recobrimento de partículas de ureia a fim de reduzir as perdas de nitrogênio por volatilização e, assim, torná-lo mais disponível aos vegetais. E o segundo objetivo, é a avaliação de uma solução recobridora, baseada na proposta por Zorzi et al. (2015), porém sem a utilização de polímeros, no recobrimento da ureia.

\section{REFERENCIAL TEÓRICO}

A produção de alimentos e o uso de fertilizantes são fatores indissociáveis no mundo atual. Com o aumento crescente da população mundial, é cada vez maior a 
procura por alimentos de alta qualidade, ricos em nutrientes. Esta tendência, a longo prazo, reforça a necessidade da utilização de nitrogênio, fósforo e potássio para proteger e recuperar a fertilidade dos solos agrícolas do mundo. O aumento na demanda de cereais está associado não apenas ao aumento no consumo de alimentos, mas também ao forte crescimento no uso industrial, impulsionado por fatores como o aumento da utilização do milho para a produção de etanol e na alimentação animal. O Brasil é um dos poucos países com capacidade para participar do processo de crescimento da produção de alimentos, por possuir tecnologias sustentáveis de produção para atingir incrementos de produtividade em muitas culturas. Com seus 550 milhões de hectares de superfície agrícola potencial, o país é classificado em $4^{\circ}$ lugar no consumo mundial de fertilizantes NPK, e em $6^{\circ}$ lugar quando se considera somente 0 consumo de nitrogênio (PROCHNOW, 2007).

A demanda por fertilizantes nitrogenados tem aumentado proporcionalmente ao incremento da população nos últimos 50 anos. Este fator, associado ao aumento do custo do fertilizante devido ao preço do gás natural, intensificam a procura por mais eficiência de uso dos fertilizantes em culturas comerciais, que atualmente situa-se entre 30 e $40 \%$. No Brasil, os fertilizantes nitrogenados mais usados são ureia, nitrato de amônio, sulfato de amônio e fosfato monoamônico (MAP). A ureia contém de 44 a $46 \%$ de nitrogênio na forma amídica e é hidrolisada rapidamente no solo a amônio pela ação da enzima urease. Ela possui baixa corrosividade, alta solubilidade e é prontamente absorvida pelas folhas (VILLALBA, 2014).

A ureia, cuja principal forma de produção é a é a reação da amônia com óxido de carbono, apresenta elevada higroscopicidade, ou seja, grande tendência em absorver água e isto reforça a necessidade de recobrimento para elevar sua resistência como fertilizante (FRANCO, J.A.M; SARAIVA NETO, A., 2007). Ela é aplicada preferencialmente via solo, no plantio ou em cobertura, e um dos cuidados necessários para aumentar sua eficiência é incorporá-la ao solo no momento da aplicação, para minimizar as perdas por volatilização (PROCHNOW, 2007).

O recobrimento é uma técnica que modifica a superfície do fertilizante, tornando-a mais resistente e impedindo que ocorra a volatilização do nitrogênio. Essa é uma técnica já usada em vários tipos de indústrias, como por exemplo a farmacêutica, onde se tem o recobrimento de comprimidos, e na indústria alimentícia, no recobrimento de balas (DONILDA, 2000). No caso de fertilizantes, um método é recobri-lo com um material pouco solúvel em água, semipermeável ou impermeável com microporos. Isto controla a entrada e a saída de água, e, consequentemente, a taxa de dissolução dos nutrientes contidos dentro da cápsula, sincronizando a liberação de nutrientes de acordo com as necessidades das plantas.

Os equipamentos mais utilizados para o recobrimento são o tambor rotativo, leitos fluidizados e de jorro, nas suas diferentes conformações. O leito de jorro tem sido tema de diversos trabalhos de recobrimento, devido à boa movimentação das partículas e ao ótimo contato fluido-partículas (COSTA et al. 2015)

Outro motivo do uso do leito de jorro é a vantagem da formação de uma camada altamente uniforme em curto tempo de processamento, devido, principalmente, às excelentes condições de transferência de calor e de massa no interior do equipamento (KUCHARSKI; KMIEC, 1983). No leito de jorro, o ar aquecido é injetado fazendo com que ocorra a formação do jorro e paralelamente, faz-se a atomização de uma solução, que irá recobrir o fertilizante, formando uma película. É importante que o ar seja aquecido para que o solvente presente na solução evapore (DONILDA, 2000). 
O leito de jorro foi desenvolvido em 1954 por Gishler e Mathur, inicialmente para utilização na secagem de grãos. Entretanto, atraiu atenção para diversas aplicações, como refrigeração, granulação, recobrimento, pirólise, entre outros (MATHUR, EPSTEIN 1974).

A Figura 1 mostra as regiões características do leito de jorro. Na região central, devido à elevada velocidade do fluido, ocorre o transporte ascendente das partículas na região de jorro. Na chamada região da fonte, localizada na parte superior do leito, ocorre movimento desacelerado das partículas, que caem na região anular. Esta, por sua vez, compreende as partículas que deslizam para baixo em contracorrente com o fluido.

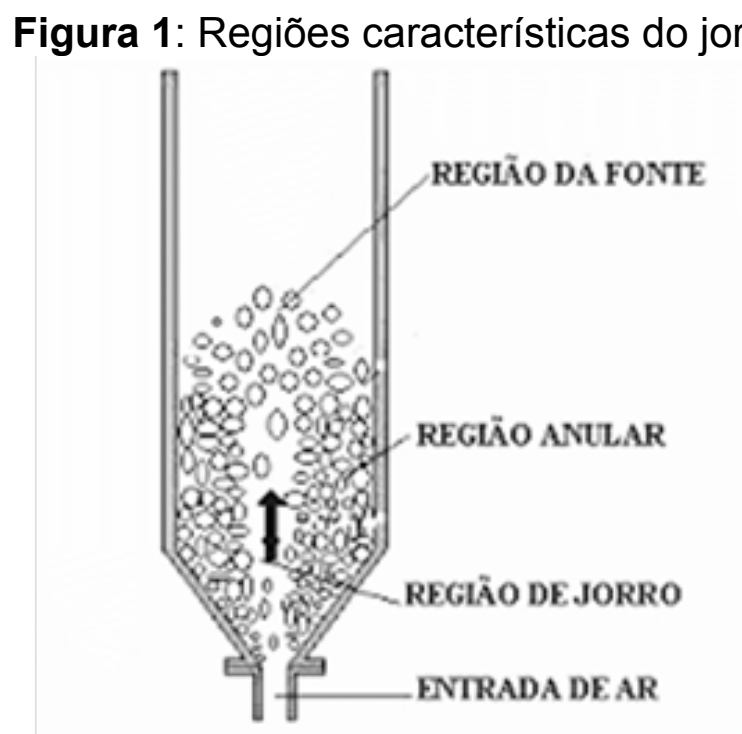

Fonte: Santos et al., 2009.

As variáveis mais importantes da operação do leito de jorro são a velocidade mínima de jorro, a queda de pressão máxima, queda de pressão de mínimo jorro e a altura máxima de jorro estável (MARRETO, 2006). O sistema possui uma curva característica, a qual é obtida variando-se a vazão de fluido e obtendo como resposta a queda de pressão. A curva possui formato como o representado na Figura 2.

Figura 2: Curva característica do Leito de Jorro.

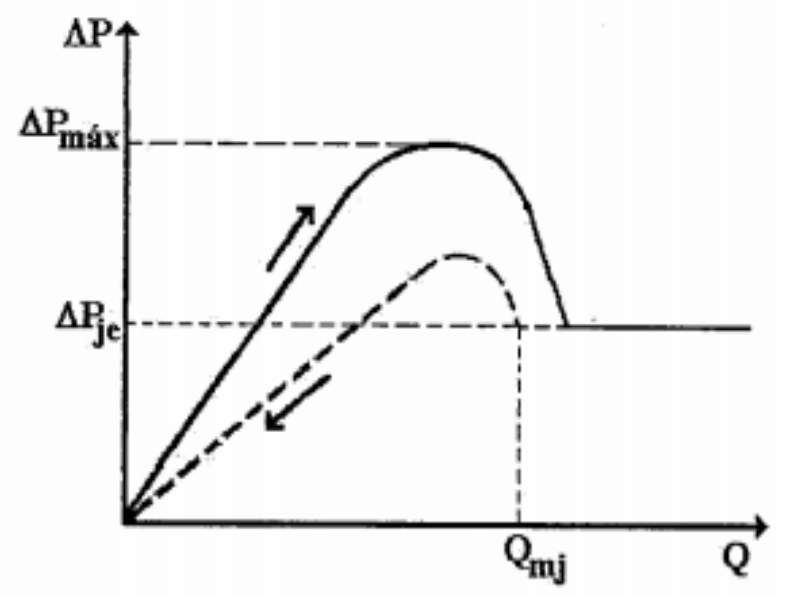

Fonte: Lima, 2004. 
Em baixas vazões, o leito se comporta como um leito fixo, exibindo uma relação linear entre a queda de pressão e a vazão. À medida em que se aumenta a vazão atingese um ponto máximo que precede a formação do jorro, e, após o máximo, a queda pressão cai bruscamente, e um jorro estável é obtido (LIMA, 2004). A descrição do leito pode ser realizada pelas Equações 1, 2 e 3, desenvolvidas por Mathur e Epstein (1974); Massarani (1987) e Malek e Lu (1965), respectivamente.

$$
\begin{aligned}
& q_{j m}=\left(\frac{d_{p}}{D_{c}}\right)\left(\frac{D_{i}}{D_{c}}\right)^{1 / 3}\left(\frac{2 g H\left(\rho_{s}-\rho\right)}{\rho}\right)^{1 / 2} \\
& \Delta P_{j m}=\frac{2}{3}\left(1-\varepsilon_{m f}\right) H \rho_{s} g \\
& H_{\max }=0,105 D_{c}\left(\frac{D_{c}}{d_{p}}\right)^{0,75}\left(\frac{D_{c}}{D_{i}}\right)^{1 / 3}\left(\frac{1}{\phi^{2} \rho_{s}^{1,2}}\right)
\end{aligned}
$$

Onde, $q_{j m}$ é a velocidade de jorro mínimo; $\Delta P_{j m}$ é a queda de pressão de jorro mínimo; $H_{\max }$ é a altura máxima de jorro estável; $d_{p}$ é o diâmetro da partícula; $D_{c}$ é o diâmetro da parte cilíndrica do leito; $D_{i}$ é o diâmetro da abertura inferior; $H$ é a altura do recheio no leito; $g$ é a aceleração da gravidade; $\rho$ é a densidade do fluido; $\rho_{s}$ é a densidade das partículas; $\varepsilon_{m f}$ é a porosidade de mínima fluidização e $\Phi$ é a esfericidade das partículas.

O desempenho de um equipamento de recobrimento pode ser avaliado com base em três aspectos: qualidade do produto, eficiência do processo e tempo de processamento. A operação de recobrimento é considerada ótima quando o produto obtido possui a qualidade pretendida, apresenta um mínimo de aglomerado de partículas e liberação do material ativo dentro das especificações desejadas.

Propostas por Kucharski e Kmiéc (1998), as Equações 4 e 5 visam avaliar a eficiência do processo de recobrimento e o crescimento da partícula, respectivamente. $O$ crescimento é definido como a razão entre a massa do filme formado durante o recobrimento e a massa original da partícula.

$$
\begin{aligned}
& \eta=\frac{M_{f}-M_{0}}{W_{s} C_{s} t \rho_{\text {susp }}} \\
& \delta=\frac{M_{f}-M_{0}}{M_{0}} \times 100
\end{aligned}
$$

Onde, $\eta$ é a eficiência do processo; $M_{f}$ é a massa de partículas após o recobrimento; $M_{0}$ é a massa inicial de partículas; $W_{s}$ é a vazão volumétrica da suspensão; $C_{s}$ é a concentração de sólidos; $t$ é o tempo do processo; $\rho_{\text {susp }}$ é a densidade da suspensão e $\delta$ é o crescimento da partícula.

Dentre os materiais usados no recobrimento, se destacam os polímeros, enxofre e ceras, que apesar da grande vantagem de reduzirem as perdas de nitrogênio, apresentam 
custos mais elevados. Porém, existem muitas pesquisas para desenvolver soluções mais baratas que diminuam essas perdas (ZORZI et al., 2015).

Zorzi et al. (2015), em seu trabalho, realizou uma série de testes com o objetivo de formular uma suspensão capaz de proporcionar a formação de um filme liso e uniforme, e com adequada concentração de sólidos, visando obter espessura de filme suficiente para minimizar as perdas de nitrogênio por volatilização. A formulação da suspensão aquosa que obteve melhores resultados apresenta em peso: $0,5 \%$ de gelatina; $0,5 \%$ de amido; $2 \%$ de polímero comercial ColorSeed®; $3 \%$ de gliceral; $9 \%$ de talco e $85 \%$ de água.

\section{MATERIAL E MÉTODOS}

\section{Projeto da Unidade Experimental}

Para este trabalho, a unidade experimental consistiu em um soprador de potência 5hp e vazão de ar de $10 \mathrm{~m}^{3} / \mathrm{h}$, seguido por uma tubulação de aço inoxidável, que realizava a alimentação de ar no leito de jorro. No topo do leito foi adicionado um borrifador para aspersão manual, mostrados na Figura 3. Um ponto de tomada de pressão foi adicionado ao leito de jorro, cerca de $5 \mathrm{~mm}$ acima da base do leito, que foi então conectado ao manômetro tubo em U (Figura 4a). Um anemômetro de fio quente foi inserido em um furo na tubulação da alimentação, imediatamente da base do leito (Figura 4a), com a finalidade de obter a velocidade média do ar e, e consequentemente a vazão de operação.

O leito de jorro (Figura $\mathbf{3 b}$ ) foi construído em uma serralheria da cidade de Uberaba-MG, confeccionado em metal, com as seguintes dimensões: $D_{c}=0,225 \mathrm{~m}$, $D_{i}=0,035 \mathrm{~m}, \mathrm{H}_{\text {cone }}=0,15 \mathrm{~m} \mathrm{e} \mathrm{H}_{\text {cilindro }}=0,85 \mathrm{~m}$. Estas dimensões foram baseadas no trabalho de Santos (2011).

Figura 3: Material utilizado. a) Soprador, b) Leito de metal e c) Borrifador com a solução recobridora.

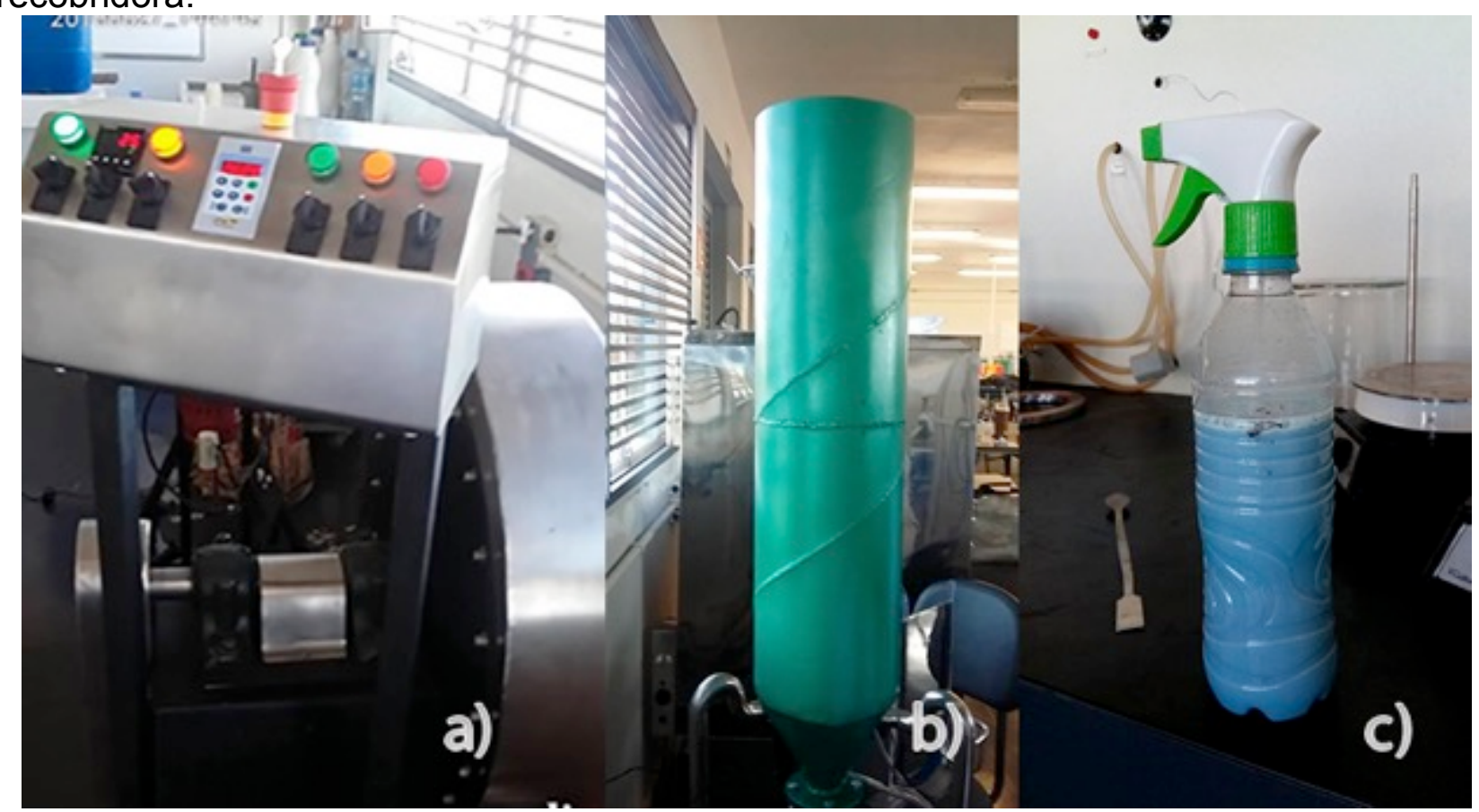



Figura 4: Acessórios da unidade
(b) anemômetro de fio quente.

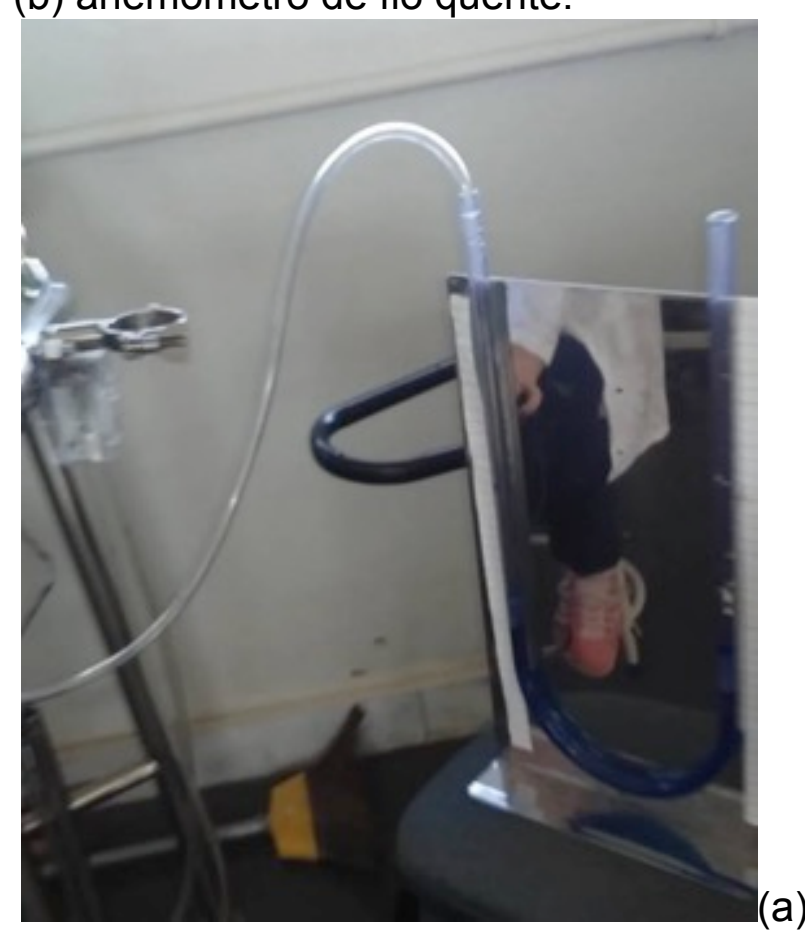

experimental: (a) manômetro tubo em U;

(a)

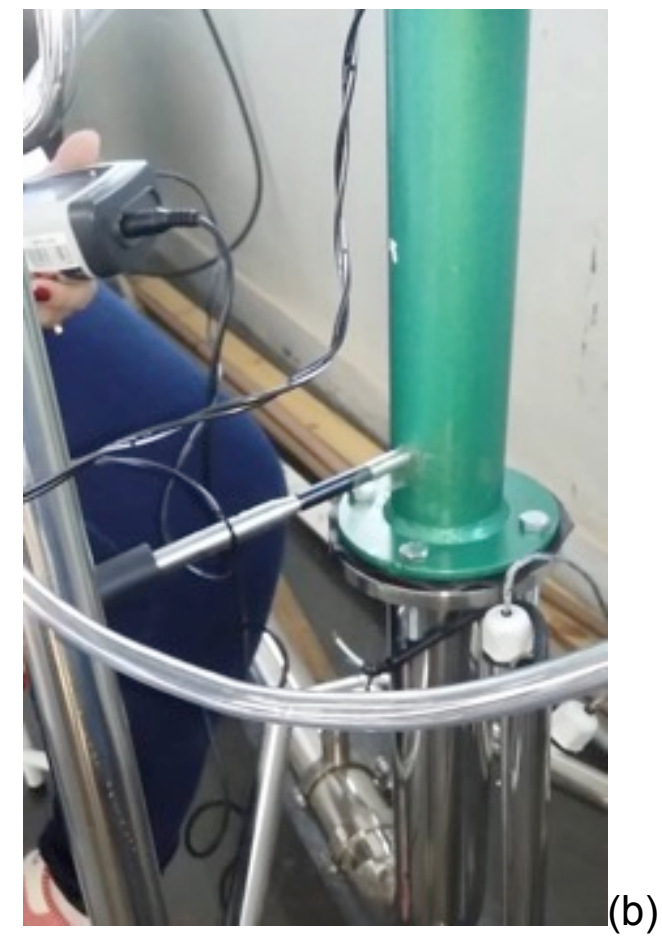

\section{Caracterização do material particulado}

Para a caracterização das partículas de ureia foram utilizadas duas técnicas. A primeira consistia em realizar um experimento, feito em triplicata, para obter a porosidade da partícula de ureia, então, as partículas foram colocadas em um béquer e pesadas e anotado a massa. Através dessa massa, calculou-se a porosidade pela Equação 6.

$$
\varepsilon=1-\frac{V_{p}}{V_{r}}
$$

Onde $V_{p}$ é o volume das partículas, calculado a partir das massas que foram medidas e da densidade da ureia obtida da literatura, pois como a ureia é higroscópica,ou seja, tem facilidade em absorver água, dessa forma ocorreria erros na medida, não sendo então possível obter um valor de densidade confiável através da picnometria. O volume do recipiente $\left(V_{r}\right)$ foi calculado a partir da altura de empacotamento das partículas e o diâmetro do béquer.

Já a segunda técnica de caracterização consistia em medir o diâmetro da partícula $\left(d_{p}\right)$ e sua esfericidade. Então, tirou-se uma foto das partículas, previamente afastadas entre si e, através do software de domínio público, imageJ, é possível medir algumas propriedades das partículas, como a área projetada da partícula, os diâmetros mínimos e máximos de Ferret, como mostrado na Figura 5. 
Figura 5: Representação dos diâmetros mínimos $(D x)$ e máximos (Dy) de Ferret.
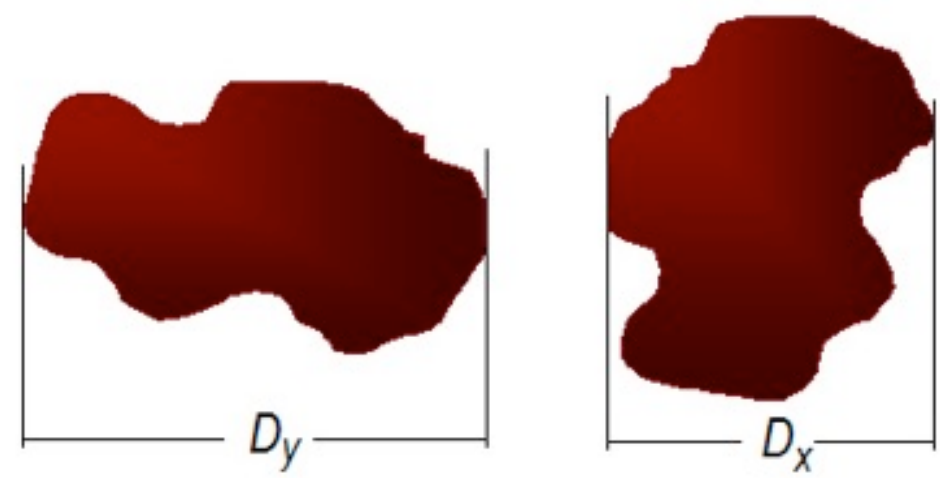

A partir dos valores obtidos no programa imageJ, se pode calcular o alongamento (A), utilizando a Equação 7.

$$
A=\frac{D y}{D x}
$$

Onde $D y$ e $D x$ são os diâmetros máximos e mínimos de Ferret, respectivamente.

Com os valores do alongamento das partículas, pode-se calcular a esfericidade de cada partícula de ureia através da Equação 8, que é uma aproximação para o cálculo usando imagens bidimensionais baseada no alongamento (PEÇANHA; MASSARANI, 1986).

$$
\phi=\frac{1}{A}
$$

\section{Preparo da solução recobridora}

Tomou-se como base a solução recobridora número 12 proposta por Zorzi et al. (2015), pois foi a que se obteve melhores resultados, entretanto, alterou-se a composição de água para $87 \%$, pois foi retirada a quantidade do polímero ColorSeed $\AA$, visto que 0 polímero era apenas para promover maior homogeneidade na superfície da partícula e este não era o foco principal do trabalho. Assim a composição utilizada foi, em massa, $0,5 \%$ de gelatina, $0,5 \%$ de amido, $3 \%$ de glicerina, $9 \%$ de talco e $87 \%$ de água. Adicionouse um corante à solução para melhor visualização das partículas recobertas, como mostrado na Figura 3c.

Um teste de bancada preliminar da solução recobridora foi feito a fim de verificar se as mudanças feitas nas composições alterariam o resultado esperado. Devido à falta de recursos/materiais não foi possível ser feito o aquecimento do fluido, no caso, o ar, nem a aspersão automática da solução recobridora. Então, optou-se por um sistema sem aquecimento e com aspersão manual, através de um borrifador.

\section{Determinação da Curva Característica do leito de jorro}

Para a determinação da curva característica, foi colocado no leito $600 \mathrm{~g}$ de ureia. A rotação do soprador foi ajustada em $5 \mathrm{rpm}$ e foi acrescida em $5 \mathrm{rpm}$ até $50 \mathrm{rpm}$ e após este valor, aumentou em 0,5 rpm. Após o jorro das partículas continuou-se aumentando a 
rotação do soprador até que a queda de pressão permanecesse constante. Com a leitura de três valores iguais de queda de pressão, iniciou-se a volta do processo, que consistia em diminuir a rotação do soprador na mesma proporção da ida.

Em cada rotação eram tomados os valores de queda de pressão, através do manômetro "tubo em U" conectado à base do leito, e de velocidade, por um anemômetro.

\section{Procedimento de Recobrimento da ureia em leito de jorro}

Com o intuito de realizar o recobrimento, determinou-se o jorro estável a partir da curva característica, trabalhando-se com uma vazão de ar cerca de $20 \%$ acima da vazão de jorro mínimo. Atingido o jorro estável, começou-se a aspersão manual da solução recobridora por um período de 10 minutos, com vazão de aspersão da solução de $7,02 \mathrm{~mL} / \mathrm{min}$.

\section{RESULTADOS E DISCUSSÃO}

Através do teste preliminar de recobrimento em bancada, observou-se uma boa adesão da solução recobridora sobre as partículas, que se tornaram azuis após o recobrimento, devido ao corante adicionado. Assim, a adição do corante se mostrou eficaz para o acompanhamento do progresso do recobrimento, como mostra a Figura 6.

Figura 6: Partícula após recobrimento preliminar

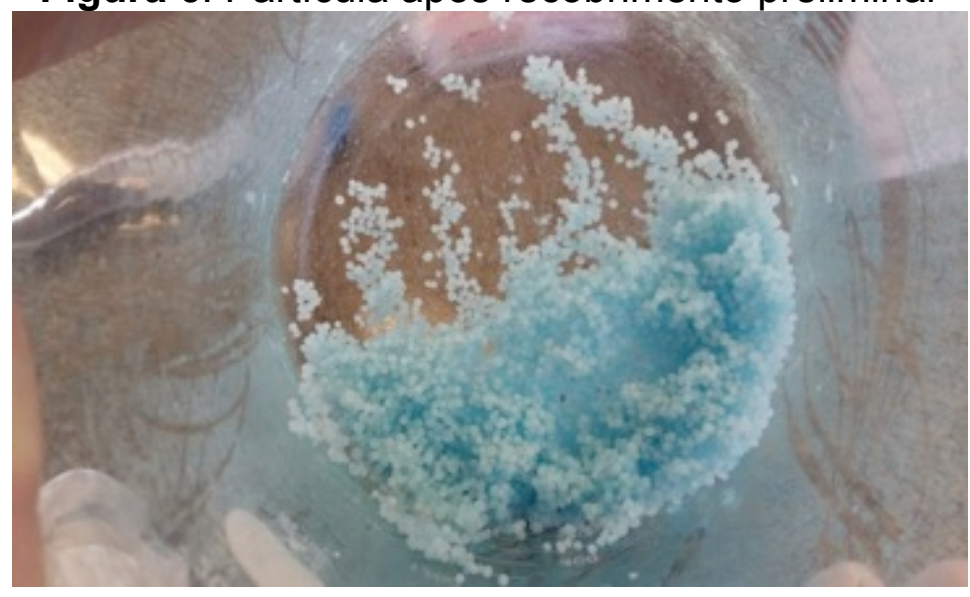

Para validação e comparação dos valores encontrados em relação à caracterização das partículas e os resultados do leito de jorro, foi usado o trabalho de Costa (2015). Foi obtido um diâmetro médio de partículas de 0,00175 m, densidade de $1340 \mathrm{~kg} / \mathrm{m}^{3}$, esfericidade $\Phi=0,65$ e porosidade inicial do leito de $\varepsilon=0,422$. Apenas o valor de diâmetro obtido teve uma maior diferença em relação ao encontrado por Costa (2015), isso pode ser atribuído a diferença entre as amostras do fertilizante.

Tabela 1: Caracterização das partículas.

\begin{tabular}{ccc}
\hline Característica & Este trabalho & Costa (2015) \\
Diâmetro médio $(\mathrm{m})$ & 0,00175 & 0,00308 \\
Densidade $(\mathrm{Kg} / \mathrm{m} 3)$ & 1340 & 1340,5 \\
Porosidade inicial do leito & 0,422 & 0,4271
\end{tabular}


A curva característica do leito de jorro foi obtida experimentalmente, com $600 \mathrm{~g}$ de ureia empacotadas em uma altura de leito estático $H_{0}=5,63 \mathrm{~cm}$. A Tabela 1 mostra os dados de queda de pressão, velocidade na secção de entrada do leito $\left(D_{i}\right)$ e vazão de alimentação de ar.

Tabela 2: Dados de queda de pressão, velocidade e vazão obtidos na curva característica do leito de jorro com $M=600 \mathrm{~g}$ de ureia e $H_{0}=05,63 \mathrm{~cm}$.

\begin{tabular}{|c|c|c|c|c|c|}
\hline \multicolumn{3}{|c|}{ Ida: Incrementando a Vazão } & \multicolumn{3}{|c|}{ Volta: Vazões decrescentes } \\
\hline$-\Delta P[\mathrm{~Pa}]$ & $V_{a r}[\mathrm{~m} / \mathrm{s}]$ & $Q\left[\mathrm{~m}^{3} / \mathrm{s}\right]$ & $-\Delta P[\mathrm{~Pa}]$ & $V_{a r}[\mathrm{~m} / \mathrm{s}]$ & $Q\left[\mathrm{~m}^{3} / \mathrm{s}\right]$ \\
\hline 9,81 & 0,03 & $5,89.10^{-5}$ & 176,58 & 3,10 & $6,08 \cdot 10^{-3}$ \\
\hline 19,62 & 0,22 & $4,32 \cdot 10^{-4}$ & 166,77 & 2,70 & $5,30 \cdot 10^{-3}$ \\
\hline 68,67 & 0,47 & $9,22 \cdot 10^{-4}$ & 161,87 & 2,30 & $4,51 \cdot 10^{-3}$ \\
\hline 156,96 & 0,77 & $1,51 \cdot 10^{-3}$ & $176,58^{*}$ & $1,96 *$ & $3,85 \cdot 10^{-3 *}$ \\
\hline 269,78 & 0,88 & $1,73 \cdot 10^{-3}$ & 153,04 & 1,50 & $2,94 \cdot 10^{-3}$ \\
\hline 294,30 & 0,93 & $1,83 \cdot 10^{-3}$ & 147,15 & 1,40 & $2,75 \cdot 10^{-3}$ \\
\hline 313,92 & 1,15 & $2,26 \cdot 10^{-3}$ & 142,25 & 1,28 & $2,51 \cdot 10^{-3}$ \\
\hline 333,54 & 1,28 & $2,51 \cdot 10^{-3}$ & 137,34 & 1,15 & $2,26 \cdot 10^{-3}$ \\
\hline 338,45 & 1,40 & $2,75 \cdot 10^{-3}$ & 117,72 & 0,93 & $1,83 \cdot 10^{-3}$ \\
\hline 343,35 & 1,50 & $2,94 \cdot 10^{-3}$ & 98,10 & 0,88 & $1,73 \cdot 10^{-3}$ \\
\hline 353,16 & 1,96 & $3,85 \cdot 10^{-3}$ & 68,67 & 0,77 & $1,51 \cdot 10^{-3}$ \\
\hline 176,58 & 2,30 & $4,51 \cdot 10^{-3}$ & 49,05 & 0,47 & $9,22 \cdot 10^{-4}$ \\
\hline 176,58 & 2,70 & $5,20 \cdot 10^{-3}$ & 19,62 & 0,22 & $4,32 \cdot 10^{-4}$ \\
\hline 176,58 & 3,10 & $6,08 \cdot 10^{-3}$ & 4,91 & 0,03 & $5,90 \cdot 10^{-5}$ \\
\hline
\end{tabular}

${ }^{*}$ Condição de jorro mínimo experimental.

A transição de leito fixo para leito de jorro pode ser observada pela Figura 7, que representa a curva característica, na qual se plota a queda de pressão em função da vazão de gás. Em baixas vazões, o ar apenas percola as partículas, que se comportam como um leito fixo. Assim, a queda de pressão aumenta gradualmente com o aumento da vazão, descompactando o leito até o ponto de máxima queda de pressão, que foi de 353,16 Pa.

Com aumento contínuo do fluxo de ar, surge uma cavidade próxima ao orifício de entrada, que pode ser observada pela brusca diminuição da queda de pressão. Então, a cavidade alonga-se dando origem a um jorro, que aflora através da superfície. A partir deste ponto, a pressão se mantém constante com o aumento no fluxo de gás, acarretando apenas na elevação da altura da fonte.

O mesmo comportamento foi encontrado por Costa (2015), porém alguns resultados foram diferentes. A partir dos dados dispostos na Tabela 1 e Figura 7, obtevese uma condição de jorro mínimo com vjm=1,96 m/s, Qjm=3,85.10-3 m3/s e $\delta P m j=176,58 \mathrm{~Pa}$. Para uma carga de 500g, Costa (2015) encontrou uma velocidade de jorro mínimo de $0,44 \mathrm{~m} / \mathrm{s}$, valor muito inferior ao encontrado. Tal diferença pode ser atribuído às diferenças nos sistemas utilizados em cada trabalho, bem como na diferença entre as partículas de ureia usadas.

Para o recobrimento foi utilizada uma solução de composição (em massa): $0,5 \%$ de gelatina, $0,5 \%$ de amido, $3 \%$ de glicerina, $9 \%$ de talco e $87 \%$ de água. Adicionou-se também a esta solução azul de metileno, para facilitar a observação visual do recobrimento.

A operação aconteceu durante 10 minutos, com vazão ar cerca de $4,510^{-3} \mathrm{~m}^{3} / \mathrm{s}$ e 
vazão de solução de $7,02 \mathrm{~mL} / \mathrm{min}$. A temperatura foi mantida constante à $24^{\circ} \mathrm{C}$ (temperatura ambiente). Foi possível observar que a maior parte das partículas recebeu a solução, porém, parte destas aderiram à parede do leito, como mostrado na Figura 8 , pois devido à baixa temperatura de operação, não houve secagem suficiente da solução nas partículas de ureia, deixando-as úmidas.

Figura 7: Curva característica experimental do leito de jorro.

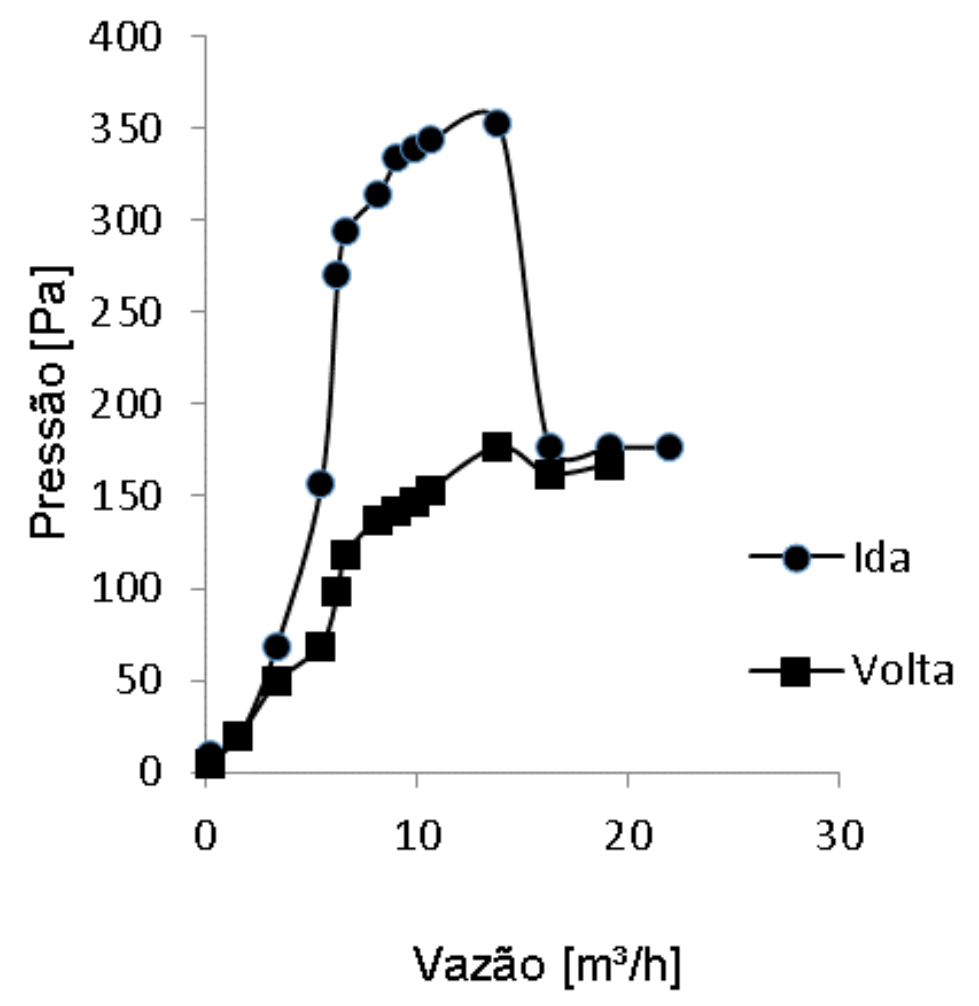

Figura 8: Partículas aderidas à parede do leito.

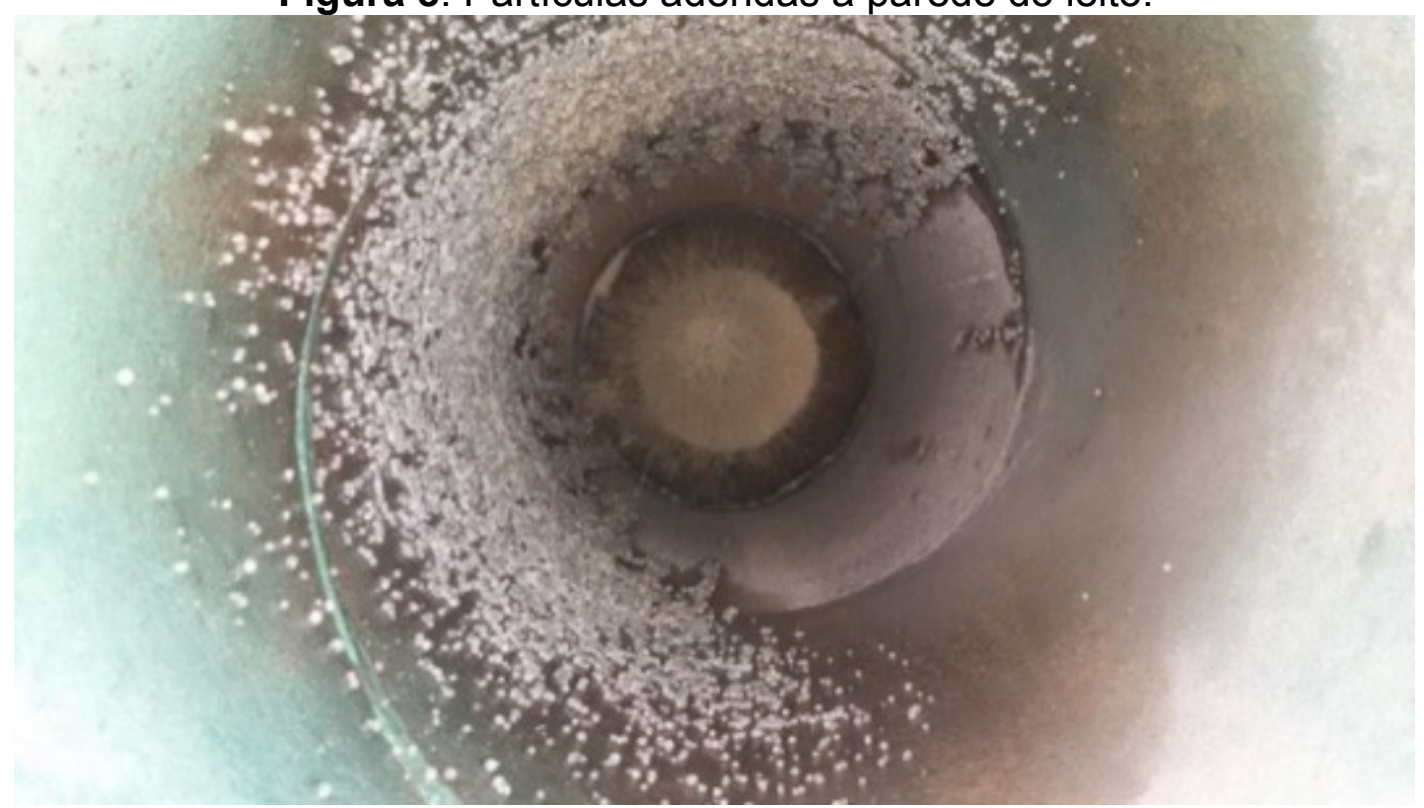


A fim de determinar a eficiência do processo e o crescimento da partícula, foi proposto utilizar as Equações 4 e 5. Porém, houve perda das partículas de ureia pela parte superior durante a corrida para atingir o jorro estável, além disso grande parte das partículas ficou aderida ao leito e não puderam ser todas recolhidas. Assim, não foi possível calcular a eficiência do recobrimento, pois mesmo com outro método, não seria possível atingir resultados confiáveis, pois muitas partículas foram perdidas no processo.

\section{CONCLUSÕES}

Através dos experimentos realizados com o leito de jorro construído foi possível determinar o valor de jorro mínimo de $3,85.10^{-3} \mathrm{~m}^{3} / \mathrm{s}$ e uma queda de pressão de jorro mínimo de 176,58 Pa, valores. O comportamento obtido foi o mesmo obtido por Costa (2015), porém com diferenças nos valores de pressão e velocidade de jorro mínimo, um estudo mais detalhado seria indicado, para encontrar os fatores que influenciaram nessa diferença.

Observou-se que as partículas da ureia foram recobertas pela solução utilizada, porém, grande parte destas aderiu à parede do leito, e então, não foi possível calcular a eficiência do processo e o crescimento da partícula. Atribuiu-se a esse fato a falta de aquecimento do ar. Sendo assim, não houve evaporação do solvente da solução, deixando as partículas muito úmidas e causando a aderência na parede do leito. Pelo mesmo motivo, houve perda de parte das partículas e não foi possível calcular a eficiência do recobrimento, visto que muitas partículas que ficaram aderidas ao leito foram perdidas.

Concluiu-se, entretanto, que o objetivo deste trabalho foi alcançado. Uma vez que foi possível caracterizar o leito de jorro construído e observar o recobrimento das partículas de ureia. Para um melhor resultado no recobrimento, têm-se como sugestão para futuros trabalhos, projetar um sistema de aquecimento viável economicamente para auxiliar no recobrimento das partículas, instalar na parte superior do leito um ciclone, a fim de capturar as partículas que se perde durante o jorro instável, acoplar o sistema de bombeamento mecânico, para evitar excesso de solução recobridora e testas novas formulações para a solução. Além disso, a solução recobridora apresentou-se eficiente, pois é uma solução barata para o recobrimento de ureia.

\section{REFERÊNCIAS}

\section{COSTA, T. P. Avaliação da fluidodinâmica e do recobrimento de grânulos de ureia} em leito de jorro para minimizar as perdas de nitrogênio. 2015. 102f. Dissertação (Mestre em Engenharia) Programa de Pós Graduação em Engenharia, Universidade Federal do Pampa, Bagé-RS. 2015.

COSTA, T. P.; ZORZI, B.; NORA, F. B. D.; WESTPHALEN, G. F.; ROSA, G. S. Otimização experimental do recobrimento de partículas de uréia em leito de jorro. Anais. In: Congresso Brasileiro de Sistemas Particulados, São Carlos, 2015.

\section{DA MOTA, E. P. Fertilizantes nitrogenados de liberação gradual: longevidade e} volatilização em ambiente controlado. Dissertação (Mestrado em Solos e Nutrição de Plantas), Universidade de São Paulo, Piracicaba, 2013. Disponível em:

http://www.teses.usp.br/teses/disponiveis/11/11140/tde-09012013-132926/ . Acesso em: 16 nov. 2015. 
DONIDA, M. W. Recobrimento polimérico de ureia em leito de jorro bidimensional. Dissertação (Mestrado), Universidade Estadual de Campinas, Campinas, 2000.

FRANCO, J. A. M.; SARAIVA NETO, A. Produção de fertilizantes nitrogenados e suprimentos de matéria-prima. Nitrogênio e enxofre na agricultura brasileira. Piracicaba: IPNI Brasil, 2007. Cap. 4, p. 127-161.

KUCHARSKI, J.; KMIEC, A. Hydrodynamics, heat and mass transfer during coating of tablets in a spouted bed. Can. J. Chem. Eng., Ottawa, v.61, n.3, p.435-439, 1983.

LIMA, P. M. Análise da fluidodinâmica e transferência de calor em leito de jorro com alimentação continua de sólidos pela base. Dissertação (Mestrado em Engenharia Química), UFSCar, 2004.

MALEK, M. A.; LU, B. C. Y. Pressure drop and spoutable bed height in spouted bed. Industrial and Engineer Chemical Process Design and Develop, v.4, p.123-128, 1965.

MARRETO, R. N. Estudo da técnica de leito de jorro convencional para secagem de microcápsulas de caseína e pectina. 2006. 102f. Tese (Doutorado em Ciências Farmacêuticas). Universidade de São Paulo. Ribeirão Preto-SP.

MASSARANI, G. Secagem de produtos agrícolas. Rio de Janeiro: Edgard Bücher, 1987. v.2, 56p.

MATHUR, K. B.; EPSTEIN, N. Spouted Beds. London: Academic Press, 1974, 303 p.

PEÇANHA, R. P.; MASSARANI, G. Dimensão característica e forma de partículas. In: ENCONTRO SOBRE ESCOAMENTO EM MEIOS POROSOS, 14., 1986,

Campinas. Anais... Campinas, 1986. v. 1, p. 302-312.

PROCHNOW, L. I. A indústria de fertilizantes nitrogenados e o futuro. Informações agronômicas, $n^{\circ} 120$, dez/2007. Disponível em: http://www.ipni.net/publication/iabrasil.nsf/0/6CEA9D9A5D2B825683257AA1005D87E3/\$FILE/Jornal120.pdf. Acesso em: 15/07/2016.

SANTOS et al. Estudo da estabilidade fluidodinâmica do leito de jorro através da fluidodinâmica computacional. IX Encontro Interno e XIII Seminário de Iniciação Científica, Universidade Federal de Uberlândia. 2009.

STAFANATO, J. B.; GOULART, R. S.; ZONTA, E.; LIMA, E.; MAZUR, N.; PEREIRA, C. G.; SOUZA, H. N. Volatilização de amônia oriunda de uréia pastilhada com micronutrientes em ambiente controlado. Revista Brasileira de Ciência do Solo, v. 37, n.1, p. 726-732, Viçosa, 2013.

VILLALBA, H. A. G; LEITE, J. M.; OTTO, R.; TRIVELIN, P. C. O. Fertilizantes nitrogenados: novas tecnologias. Informações agronômicas, $n^{\circ}$ 148, dez/2014. Disponível 
em:http://www.ipni.net/publication/iabrasil.nsf/0/8A8C436B98265A2983257DB6006A962D /\$FILE/Page12-20-148.pdf. Acesso em: 13/07/2016.

ZORZI, B. et al. Formulação e Caracterização de suspensão para recobrimento de ureia. In: XI Congresso Brasileiro de Engenharia Química em Iniciação Cientifica. 2015. Campinas-SP.

Recebido em: 29/10/2018

Aprovado em: 23/04/2018 